August 1986

\title{
Body-Snatching: Medicine and the Cartesian Threat
}

Mark D. Sullivan, MD, PhD

University of Washington, Seattle Washington

Follow this and additional works at: https://jdc.jefferson.edu/jeffjpsychiatry

Part of the Psychiatry Commons

Let us know how access to this document benefits you

\section{Recommended Citation}

Sullivan, MD, PhD, Mark D. (1986) "Body-Snatching: Medicine and the Cartesian Threat," Jefferson Journal of Psychiatry. Vol. 4 : Iss. 2 , Article 8.

DOI: https://doi.org/10.29046/JJP.004.2.005

Available at: https://jdc.jefferson.edu/jeffjpsychiatry/vol4/iss2/8

This Article is brought to you for free and open access by the Jefferson Digital Commons. The Jefferson Digital Commons is a service of Thomas Jefferson University's Center for Teaching and Learning (CTL). The Commons is a showcase for Jefferson books and journals, peer-reviewed scholarly publications, unique historical collections from the University archives, and teaching tools. The Jefferson Digital Commons allows researchers and interested readers anywhere in the world to learn about and keep up to date with Jefferson scholarship. This article has been accepted for inclusion in Jefferson Journal of Psychiatry by an authorized administrator of the Jefferson Digital Commons. For more information, please contact: JeffersonDigitalCommons@jefferson.edu. 


\title{
Body-Snatching: Medicine and the Cartesian Threat
}

\author{
Mark D. Sullivan, M.D., Ph.D.
}

\section{INTRODUCTION: LESSONS FROM HORROR}

Twentieth century physicians are proud to be biological scientists. It is this feature above all others that distinguishes us from our predecessors. Because it is the badge of our progress in medicine, biology is often considered the essential core of medical care. Indeed, we can become so focused upon the biology in medicine that all other aspects of caring for patients fade into a murky background of ill-defined sentimentality.

Sometimes it is necessary to look outside of medicine if we are to reawaken ourselves to the broader role of medicine in society. One unlikely but fertile source of insight about medicine is the classic horror movie Invasion of the Body Snatchers, made in 1956 and, to a somewhat lesser extent, the 1978 remake of this movie. In both of these movies we are presented with the possibility that those people who we know the best and love the most may be imposters. We thus confront the fear that our intimacy and affection for the people closest to us may be for naught. Viewing the movie as physicians, we must confront the fact that "body-snatching" is taken by all concerned to be a medical problem.

In these movies body-snatching takes place as follows. Aliens arriving through 'deep space' from a dying planet fall to earth where they take root and grow into giant pods. While their victim sleeps, a duplicate of the victim grows within the pod. After differentiating into an identical replica of the human, the new body awakens from the pod while the original body withers away. Having snatched a body for its use, the alien assumes the roles and relationships of the person whose body he now inhabits.

The movies begin with scattered people complaining to some trusted authority (a small-town doctor in the original, a public health field-investigator in the remake) that their loved ones are 'different,' that they are no longer the same people. In the original, Jimmy Grimaldi complains, "She isn't my mother; don't let her get me." When Wilma Lenz is asked how the new Uncle Ira is different from the old Uncle Ira she replies, "There is no difference you can actually see. He looks, sounds, acts, and remembers like Uncle Ira."

In their fear of the body-snatchers, the citizens of Santa Mira mimic a psychiatric syndrome described by the French psychiatrist Capgras in 1923 (1).

Dr. Sullivan is a third-year resident at the University of Washington, Seattle, Washington. 
The essential feature of Capgras' syndrome is the delusion on the part of the one afflicted that persons who are very important and familiar to him have been replaced by doubles (2). Indeed, the syndrome sometimes takes the form where the doubles are seen as invaders from outer space (3). This syndrome has always been found in the context of another psychosis, usually schizophrenia. It is described as intellectual recognition in the absence of emotional familiarity (somewhat the inverse of déjà vu). It has been explained both neurophysiologically (4) and psychodynamically (5). My purpose in this essay is not to seek a better explanation for this syndrome. It is rather to examine the impact of this threat of the dissociation of intellect and feeling, of body and soul, upon society and medicine as a whole.

For those whose bodies have been snatched, body and soul have been disconnected. Their body no longer manifests their soul's reality. Externally, nothing is different, while internally, nothing is the same. The appearance of these people now belies rather than reveals their reality.

This dissociation of body from soul and appearance from reality repeats as drama the very situation into which Rene Descartes placed himself at the beginning of his famous Meditations. Descartes' purpose in these Meditations was to discover a secure foundation upon which a "firm and permanent structure" of scientific knowledge could be based. As a first step toward this goal, Descartes sought to free himself of the scholasticism that dominated the intellectual climate of his day. He wanted to make possible a body of natural sciences unencumbered by Aristotelean metaphysics. To this end, he sought to "... seriously and freely address myself to the upheaval of all my former opinions." He thus employed a 'method of doubt' according to which he agreed to ". . . withhold my assent from matters which are not entirely certain and indubitable."

In pursuing this method, Descartes did not scrutinize each of his beliefs singly, "which would be an endless undertaking," but sought to discover and discard all the dubitable beliefs that underlie our knowledge. By subjecting those basic beliefs that we take most for granted to the most severe doubt possible, Descartes sought to find absolutely indubitable beliefs to serve as the foundation for his edifice of knowledge. However, to mount and sustain such a doubt was no easy task. To proceed from the possibility that any of our beliefs might be false to the possibility that all our beliefs might be false is an implausible inference for which even Descartes had difficulty providing a reasonable basis: "How are we to deny the obvious without being mad?"

To make his hyperbolic doubt plausible, Descartes postulated an evil demon with the capacity to separate appearance from reality: "I shall then suppose, not that God, who is supremely good and the foundation of truth, but some evil genius not less powerful than deceitful, has employed his whole energies in deceiving me..."(1). The evil demon is the vehicle by which he makes concrete what I will call "the Cartesian threat": that what we see may tell us nothing of 
what truly exists, that the behavior of others may reveal nothing of their true beliefs.

Insofar as this threat of universal error applies to our knowledge of other people, it is the same threat as that posed by the body-snatchers. For Descartes under the method of doubt, as well as for those inhabitants of a world in which body-snatchers are known to be loose, proof must precede trust. Each person is not himself until he is proven to be. This is a remarkable inversion in both common sense and common decency. It is the genius of these movies that they effectively dramatize this interpersonal state. By looking at the Invasion of the Body-Snatchers movies as dramatizations of the Cartesian threat of universal deceit, pretense and dissimulation, we will be able to see that this threat is not merely an epistemologist's pedantry, but an inchoate evil that haunts our daily lives.

Opposite this danger lies the safe haven to which we run. In these movies the Cartesian threat calls forth a medical response. For all the miracles of modern medicine, it remains curious that the dissociation of soul from body is considered a problem for physicians. Precisely why is the Cartesian threat of universal dissimulation considered a medical problem? Examining this question will allow us to better understand how the role of medicine in society extends beyond its battle with bacteria, cancer, and heart disease. We will see how medicine functions as both defender against the Cartesian threat and as itself a perpetrator of this threat. Throughout, I will focus specifically on the Cartesian dissociation of proof from trust. I will not discuss Descartes' own ideas about medicine which have been discussed recently elsewhere (7).

\section{BODY SNATCHING AS THE WORK OF DESCARTES' DEMON}

The special talent of Descartes' demon is to systematically disconnect appearance from reality. In our everyday lives we may misinterpret any given appearance. We all live with the natural threat of occasional error: that may not be Aunt Betty in the distance but some other woman. The general and systematic dissociation of appearance from reality perpetrated by Descartes' demon is a problem not merely of greater degree, but of an entirely different kind. After such a dissociaton, evidence leads away from rather than toward truth. There remains no reliable means to distinguish mere appearance from reality.

In the original movie, the psychiatrist, Dan Kaufman, evokes just this state as he admonishes Dr. Bennell after Bennell reports he has found a copy of his friend Jack growing on his billiard table: "Men, women, and children had just discovered that their relatives weren't their relatives at all. So your mind started playing tricks and reality became unreality. The dead man became Jack's double in your eyes." He goes on to explain that he is convinced Bennell is reporting appearance accurately but that it has nothing to do with reality. "It happened in every detail, but only in your mind." By separating appearance from reality the 
demon isolates us in our mind apart from the real world and from other people.

Each human has the capacity to dissociate his personal appearance from his personal reality. That is, each of us can dissemble or dissimulate by hiding under a false appearance. This is most obvious in cases of prolonged or elaborate deceit such as that of a traitor or spy. For these people, loyalty, patriotism, and indeed the vast majority of their lives, can become mere appearance.

Two things are unique about this dissociation as it is found in Descartes and in these movies. First, the Demon and the Body-snatchers impose the dissimulated state. Their victims do not choose to deceive. This produces the second unique aspect. Dissimulation ceases to be a specific act and becomes an enduring state; it becomes the rule rather than the exception in human interaction. In a way independent of the victim's will, his human body is transformed into a human guise. The victim's body is now a mask that conceals rather than reveals his true nature. Thus sudden and total transformation is new to Dr. Bennell: "In my practice I've seen people's humanity drain away, but slowly, not all at once." Once snatched, people are no longer able to express feelings or perhaps even to have them.

This erosion of trust served Descartes' purposes well. He hoped to replace trust with proof in all matters of knowledge. He sought to take nothing for granted and thereby build a secure foundation for knowledge once and for all. Trust, like faith is always vulnerable to doubt and will be systematically suppressed in a method of doubt.

In the original movie, this erosion of trust produces the rapid erosion of the community. Objectively, the community is being taken over by aliens in familiar human bodies. This is enough by itself to destroy the most stable of communities. Yet, running before this like a wave through the town is the subjective sense of distrust. People cease to rely upon the web of interrelations that hold the community together. Neighbors, police, the telephone company are successively co-opted. Through all this travail they rely first and last upon their physician.

\section{MEDICINE AS THE DEFENDER AGAINST THE BODY SNATCHERS}

At the beginning of the original movie, we see Dr. Miles Bennell hurrying back from a medical convention in response to an urgent message from his nurse. His patients have been demanding to see him for two weeks but won't tell anyone else why. There is a rumor about people who believe their relatives are imposters. Upon arriving in town, Dr. Bennell ruminates “. . . everything looked the same but wasn't . . . something evil had taken possession of the town."

Here at the beginning of the film, so early as to almost escape notice, it is established that body-snatching is a medical problem. Without any prompting by those in authority, the populace decides that this inexplicable transformation in their loved ones is something to bring to the attention of their family doctor. 
Eventually a psychiatrist is also consulted, but the clergy are conspicuous in their absence.

The people of Santa Mira expect Dr. Bennell not only to know what to do for those snatched but also to be able to determine who has been snatched and what that consists of. Becky queries: "What's going on? Maybe you can tell me-you're the doctor." That is, he is expected to perform tasks of both medical therapeutics and diagnosis. In the beginning this presents the difficult problem of determining whether it is the one transformed or the one witnessing the transformation that requires treatment. Dr. Bennell chastens Wilma Lenz, "No one could impersonate your Uncle Ira without your seeing a million little differences. ... When you see this you will realize the trouble is inside you."

The nature of the trouble inside Wilma Lenz or, for that matter, inside her Uncle Ira, is not immediately clear. Wilma could be perceiving things falsely due to some disorder inside her mind or Ira could be acting oddly due to some disorder inside his body. The problem could be psychiatric or medical.

Insofar as the problem is thought to originate inside the body of those afflicted it is interpreted as a medical disorder. This is consistent with contemporary medical practice. Problems within society are deemed medical insofar as they appear to spring from sources intrinsic to the body.

Since approximately 1800 when autopsy-based clinico-pathological correlation became the gold standard in medical diagnosis, the desire to know the nature of disease has taken the form of a desire to open the body so as to be able to look inside. Thereby, as Michel Foucault explains in his The Birth of the Clinic (8), the physician can directly confront disease with his own eyes. The lesion visible within the patient's body is the now sensible source for the patient's symptoms. The physician no longer need rely solely upon the patient's report of his illness; he can open the body and see the disease itself. Cirrhosis of the liver and emphysema of the lungs thus cease to be experiences originating in the darkness of our bodies, for now they can be directly seen. This desire to open bodies to get to the bottom of things medical can be found in the original movie.

Miles is called to his friend Jack's house because Jack has discovered a body on his billiard table. Miles is expected to diagnose the situation. Adopting the medical attitude, he remarks that "... (the) face is vague . . . (the) body has all its features but no detail. It is not a corpse-what else could it be?" The body is not alive, but it is not a usual dead body either. The distinctively medical impulse of Dr. Bennell is to open the body to find out what is going on. He checks his impulse, however, with these words. "It sounds crazy, but if I did an autopsy, I'd find every organ in perfect condition. As perfect as the body is externally, everything in working order." Dr. Bennell already senses, albeit vaguely, that body-snatching is not a disease that can be known in the usual medical manner. Body-snatching is a disease of the soul, an organ not easily revealed at autopsy.

To the extent that Dr. Bennell's task of defending the populace is a task of 
medical diagnosis, he must be able to determine: who is already snatched? At the beginning of the movie this consists in determining whether it is Jimmy Grimaldi or his mother who is sick, whether Wilma Lenz or her Uncle Ira has changed. By the middle of the movie the task simply becomes one of determining who can be trusted. One cannot trust the body-snatchers to admit that they have been snatched. One cannot rely upon trust to determine when trust is appropriate. Medical diagnosis, if it is to be useful here, must be able to determine whether someone has been snatched or not without relying upon their veracity.

The attempt to know another person in a way immune to that person's capacity to conceal his true thoughts and feelings is distinctively Cartesian. It is based upon the idea that to know another we must know the one inside the body. One must not trust the body, but rather peel back its covering to confront directly the feelings inside. The postulated power of Descartes' Demon means that behavior may tell nothing of belief. In the presence of this Demon-or the body-snatchers - we must assume that the appearance of the other belies his reality. In order to know the other's experience, therefore, we must gain an access to it more immediate and foolproof than his own words. The diagnostician of body-snatching must find a way of inferring from outer behavior to inner belief that is independent of the will of the one being known. As the philosopher Stanley Cavell has explained, this absolute suspicion of the other translates into a temptation to penetrate the other, to look inside his experience-or his body-to determine what is really there (9). In its impulse to cpen the body, medicine seeks to root out the body snatchers and defeat the Demon.

It is likely that all these attempts to directly confront the snatcher's soul would fail. The inside of snatched bodies would look as human as their outside does. Even Dr. Bennell realizes that to open the body on Jack's billiard table would likely reveal nothing abnormal. We would be able 'to see inside,' but the Cartesian impulse to bypass the other in order to know him would be thwarted. We would not have achieved a way of comparing what the other shows outwardly with what is going on inside his experience. The body would conceal our true nature no more or less if it could be seen through, if it were completely transparent. It would remain impossible to actually get inside another's experience through this window, or to share their sentience. Stanley Cavell in The Claim of Reason comments on the revelatory power of this frustration:

But if looking inside might not settle the question whether the friend is a human being, why isn't this more interesting than ever, or, if you like, more amazing than ever? And doesn't this at least suggest that we cannot know that another is sentient? (5)

This failure is interesting, as Cavell emphasizes, because it teaches us that our knowledge of another's sentience, of another's humanity, must have a different basis than our knowledge of his body. The experience of the patient is not accessible in the same way that his body is. The body can be directly observed, both inside and out. The patient can always conceal his experience 
from the observing eye. Observation can prove its assertions about the body; the patient must be trusted to reveal his experience.

\section{MEDICINE AS PERPETRATOR OF THE CARTESIAN THREAT}

In its battle against the body-snatchers, medicine is decisively antiCartesian. Dr. Bennell's attempt to identify those who have been snatched means he must joust with the Cartesian demon. As valiant as he may be in this, he is doomed to fail. As improbable as the Cartesian threat of total dissimulation by another may be, once it is established as a real threat, it is impossible to defeat. If we must get inside the other's experience to know him, then we will never know him.

Nevertheless, through a subtle modification in the Cartesian threat, medicine manages to defeat it in real life. Medicine, in the last analysis, also seeks to know the patient by penetrating his body. After a confusing and unsuccessful clinical course, all medical eyes turn to the autopsy for answers. Clinicians attend clinicopathological conferences to discover where they went wrong, to discover what disease was really present. The body is opened and the disease is revealed.

Disease is not only discovered but identified and defined by this means. A patient comes to the physician with a pain or other disability that he is experiencing. This disability acquires its identity as disease, however, according to the model of the autopsy, in manner entirely independent of the patient's experience of it. Medicine excludes the patient as sentient in its ultimate identification and definition of disease. Medical diagnosis is thus able to overcome any shortcomings in the patient's perception of his disease, whether these be due to ignorance or deceit. Medicine has achieved a way of knowing its patients that does not rely on their truthfulness or their capacity for selfinterpretation.

Medicine succeeds at this because its goal is humbler than that of the Cartesian. Medicine does not seek a way to indubitably know the experience of the other entirely without his cooperation as the Cartesian does. Medicine merely seeks to know the disease of the other independent of his cooperation. It is in the distinction between the experience of the disease and the disease itself that the key to medicine's success in knowing the other lies. Because it pursues a mind-independent disease, medicine need not penetrate the experience of the other-only his body. Inflamed meninges and the inflamed appendix can be seen and known independently of patients' knowledge or interpretation of them. Their primary reality is no longer experiential, as might be explored through dialogue with the patient, but pathological, something encountered through the autopsy or one of its surrogates such as x-rays or biopsies.

Though medicine's response to the Cartesian threat is not itself classically Cartesian, because medicine accepts the threat as real and operates as such, it perpetuates the power of the Demon. Because ultimate reliance upon the patient's report of his disease experience has been replaced by the direct 
encounter of physician and disease at autopsy as the best evidence for medical diagnosis, patients' reports receive less attention. They fall to the wayside as incomplete, uninformed, unreliable-as ultimately dispensible. They may be false through no fault of the patient, or through his deliberate deception if the patient is malingering. By setting aside the patient's experience in the ultimate definition and identification of disease, medicine, in effect, assumes that the patient might always be guilty of deceit, or more commonly, ignorance. Medicine thus operates as if Descartes' Demon hovered over the encounter between patient and physician, all his malign power intact. As a perpetrator of the Cartesian threat, medicine is itself a body-snatcher. When a patient first comes to the doctor, the only awareness of disease present is his own. The disorder in his body and his awareness of it are intimately linked. Together, they form a disability that disrupts his life. As the physician becomes acquainted with the patient's illness by means of history, physical examination and laboratory tests, it is transformed into disease-something defined biologically-completely independent of the patient's awareness of it. The body afflicted with this disease has been transported from the patient's awareness into that of medical professionals, tools, and institutions. The patient's interpretation of his malady is now superceded by the medical interpretation. This sickness is now defined and identified within a medical awareness that is no longer his own. His body has been snatched.

\section{CONCLUSION: SNATCHING BODIES BACK}

There is no hope offered that the citizens of Santa Mira might find a way to snatch their bodies back from the aliens. But in real life there is hope that we may be able to snatch our bodies back from contemporary medicine.

The recently elaborated distinction between disease and illness should help us understand how this might occur. Eric Cassell, a reflective internist, has described illness as "what the patient feels when he goes to the doctor," and disease as ". . . what he has on the way home from the doctor's office. Disease, then, is something an organ has; illness is something a man has" (6). Arthur Kleinman, a psychiatrist and anthropologist, explains that sickness is initially experienced by patients as illness: “. . . the life concerns and problems that it presents for common sense understanding as part of the everyday world of the sick person." Biomedical disease, on the other hand, is the "... mechanical break down or disruption in biological structures and functions" (10). Thus, disease is a way of characterizing bodily disorder in a way independent of the patient's awareness of it. Disease is defined and identified independent of the patient's capacity for self-interpretation; it is mind-independent. Illness is mind-dependent with respect to the patient. Illness is defined and identified by means of the patient's capacity for self-interpretation.

As the autopsy became incorporated into clinical medicine in the nine- 
teenth century and clinicopathological correlation became the final word in knowing disease, it became possible to define "disease" in a manner independent of illness. At some point in the contemporary encounter between doctor and patient, a backache with fever that prevents a mother from going to her son's graduation becomes pyelonephritis, an infection in her kidney. It is in this transformation from having an illness to having a disease that one's sickness and one's body are snatched.

There are many benefits to having one's sickness snatched. Transported into the technologically supported system of medical awareness, sickness is more likely to be cured. As has been well-documented, however, being plugged into this system can be intensely dehumanizing. The technological imperatives of modern medicine are diverse and powerful. They have altered the nature of birth and death in our society. Medicine assuages our fear of disease by giving us somewhere to go, something to do. But its priorities are not always our own. Sometimes it seems as if we must give up control of our lives in order to save them. Intensive-care nurses are often the first to say that they would never be a patient in one of the units where they work.

High-tech medicine is accepted as having many negative side-effects. What is less accepted is that an exclusive focus on the biological and chemical may not be the most effective means of dealing with disability, may not be the best way to get medicine's main job done. Isolation of biological factors from others relevant to healing can be detrimental to the efficiency and effectiveness of medicine. This is especially true in the case of chronic diseases such as diabetes where good care requires active patient participation. It is also true in those common situations where primary care physicians confront somatic equivalents of depression or anxiety in their patients. The relentless "rule out" of organic causes in these situations can be wasteful (e.g., coronary arteriograms for panic disorder) or even misleading (e.g., the silent gallstone seen as cause for functional abdominal pain).

This debate is far beyond my scope here. I will just mention in passing that at issue here is the very identity of medicine as a science. Is medicine a purely natural science which limits its concern to disordered biology? Or is it more effectively seen as a human or social science which fundamentally addresses the experience of disability? A move from the former to the latter will be necessary if medicine's body-snatching propensities are to be curbed.

The fears of the people of Santa Mira as the body-snatchers begin to take over are fears we each know too well. These very worldly fears include the fear of isolation, of solitude, of non-communication. They also include fears of revealing oneself and, perhaps more poignantly, of being unable to reveal oneself. Notably, these are the same fears sickness imposes on us. Each of us fears death, and perhaps more so, the disease and pain that will precede it. But even when this fate is accepted, the fear of dying alone remains almost universal. To face horrible pain totally alone, to pass from life without a whisper of concern 
from another, these are dire prospects even after one has accepted the inevitability of death itself. Those who care for us in sickness must respond to this threat of isolation as well as the threat of death.

If our sojourn with the body-snatchers has taught us anything about Cartesianism in medicine, it is that the relation between soul and body within modern medicine must be understood in terms of the dynamics of proof and trust between doctor and patient. I have addressed this issue in more detail elsewhere (11). For now, it must suffice for us to understand slightly better how proof and trust in medicine help us face death.

Proven knowledge is secure knowledge. It stands firmly in the face of death. When isolating the cause of biological death we want to be sure of what we know. The stakes are too high to accept anything less. We seek to deny death its power not only over our bodies, but over our knowledge as well. The Cartesian canons of proof were designed to produce knowledge that would escape death.

Trust is a basis for knowledge that accepts its limits in a way that proof does not. Always founded upon uncertainty, it accepts the finitude of our knowing. Trust shares our fear of death: that all will not be finished, complete, or sure when we die.

Clearly, both proof and trust have a role in the doctor-patient relationship and in medicine as a whole. We expect the scientific physician to pursue knowledge of our sickness with a rigor commensurate with the highest standards of proof. We also expect that we will be able to share our experience of sickness with our physician even though nothing about it can be definitively proved. It is this experience that first brings the patient to his physician. From the patient's point of view it is the sine qua non of medicine.

In a relatively short time medicine has acquired immensely powerful tools for diagnosis. Now it must employ those tools in a way that does not deny patients' sentience. The people of Santa Mira would understand only too well this need to have one's existence and experience confirmed by other humans.

\section{REFERENCES}

1. Capgras J, Reboul-Lachaux J: L'illusion des “sosies" dan's un delire systematise chronique. Ann Med Psychol 81:186, 1923

2. Freedman AM, Kaplan HI, Sadock BJ: Comprehensive Textbook of Psychiatry, 3rd ed. Baltimore, Williams and Wilkins, 1980

3. Moskowitz JA: Capgras' symptom in modern dress. Int J Child Psychother 1:45, 1972

4. Hayman MA, Abrams R: Capgras' syndrome and cerebral dysfunction. BrJ Psychiatry 130:68, 1977

5. Arieti S, Meth JM: Rare, unclassifiable, collective, and exotic psychotic syndromes, in American Handbook of Psychiatry. Edited by Arieti S. Basic Books, New York, 1959, p. 548

6. Descartes R: The Philosophical Works of Rene Descartes, Edited by Haldane E, Ross GRT. Cambridge: Cambridge University Press, 1911, p. 148 
7. Carter CF, Richard B: Descartes' Medical Philosophy, Baltimore, Johns Hopkins University Press, 1983

8. Foucault M: The Birth of the Clinic, Translated by AM Sheridan Smith, New York: Pantheon Books, 1973, p. 124-149

9. Cavell S: The Claim of Reason, Oxford: Oxford Univ. Press, 1979, p. 380-381

10. Ibid. p. 407

11. Sullivan M: In what sense is contemporary medicine dualistic? Culture, Medicine, and Psychiatry (in press) 